Outlines-2001-2.qxd 23-11-01 10:27 Side 5

\title{
New Tools in Social Practice: Learning, Medical Education and 3D Environments
}

\begin{abstract}
Summary
Learning with different kinds of ICT-based tools is an important issue in today's society. In this article we focus on how design of technology rich environments based on state of the art learning principles can give us new insights about how learning occur, and how we can develop new types of learning environments. Medical education constitutes the subject domain. There has been a considerable effort to develop 3D technologies in this field, and the article provides a careful review of how these technologies are applied. There is, however, a substantial gap between these advances and the use of technologies in medical education. Related work proposes individualistic assumptions or metaphors that do not focus explicitly on learning and technology mediation. Based on theoretical analysis of previous literature in the field we argue that there is a need for a new unit of analysis that includes the relationship between individual and collective activity and the role of technology herein. The socio-cultural and especially activity theory is taken as the perspective which gives the possibility to develop the argumentation about the unit of analysis. The unit of analysis also has implications for design of 3D environments. The design principles are elaborated upon and examples are given in relation to an application called Matador (Medical Advanced Training in an Artificial Distributed Environment). Matador is aimed at developing a simulation environment for training in emergency medicine.
\end{abstract}

\section{Introduction}

7 he research on computer-supported collaborative learning (CSCL) is in some respects a new field, which is growing quite fast. ${ }^{1}$ Based on socio-cultural assumptions about learning and human development, information and communication technologies can help us move from traditional instructor-centred teaching where the focus is on individual learning, to collaborative learning. Collaborative learning is defined as a collective knowledge building process where students actively generate, access and organise information. This collective process leads to a change in the student's ability and effort to take part in a learning activity. In the 1990s there have been considerable efforts to develop computer systems that can provide new types of learning environments for students (Jonassen \& Land, 2000). ${ }^{2}$ A recent review of CSCL research shows, however, that the CSCL field is not very coherent (Lehtinen, Hakkarinen, Lippo-

\footnotetext{
1 The first CSCL conference was at Indiana University in 1995. The first E-CSCL was in Maastricht in 2001.

2 Jonassen \& Land (2000) give a good general view of many important attempts, especially in USA.
} 
Krummel, 1999). In addition, 3D environments are proclaimed to be appropriate for supporting activities that include model building and problem solving (McLellan, 1996), and are as such designed with a specific subject domain and content in mind. Furthermore, 3D generated objects and avatars often constitute basic aspects of the designs. The 3D-generated objects are tools that are manipulated and moved by actors that in turn are represented by avatars.

These specific features make 3D environments different from other types of virtual environments like, e.g. Web-based environments. We argue that the unique features and qualifications of 3D environments have to be explicitly considered in analysis as well as in designs. However, technological advances have unquestionably driven the design of 3D environments. Hoffman \& Vu (1997) point to the fact that there is a substantial gap between the technologies available today and the technology that is needed for realizing the expectations for 3D-technologies as tools for learning and collaboration. There are recent and limited insights into what the nature of the collaborative processes in a predominantly $3 \mathrm{D}$ environment is like. To obtain a deeper understanding of this, we wish to step back from the technical push to explore the specific conditions of these processes. These conditions, we argue, can only be properly understood by extending the unit of analysis from technology and pedagogy themselves to the social contexts in which the 3D environments are being used. This core argument throughout the paper is outlined by suggesting activity theory as a powerful framework for understanding learning activities in different kinds of environments and for informing designs associated with virtual 3D learning environments.

The field of medicine is chosen as a prototypical field to investigate. There exists a rich body of computer-based applications and position in space (Gorman, Meier \& 
Outlines-2001-2.qxd 23-11-01 10:27 Side

OUTLINES • No. 2 ・ 2001

aimed at supporting learning and training within various areas. So far, few have emphasised the potential of 3D environments like the field of medicine. In the first part of the article we review the literature on 3D in medical education and emphasise what has been in focus so far, and we summarise this from a learning perspective. The argumentation put forward in this part represents a theoretical analysis of the field. In the second part we argue for a new theoretical framework for analysis and design. In the last part we will, with a basis in the theoretical framework, suggest a set of design principles connected to 3D environments. Here we will use a concrete 3D environment, Matador, as an example.

\section{D environments: A review of the literature in medicine ${ }^{3}$}

I $n$ the field of medicine various domain specific computer systems have been developed in areas such as anatomy, anatomy of the brain, surgery, dissection of bones and endoscopy. In surgical education the arguments for using 3D environments are found in various communities. We find insights achieved within surgical interventions particularly interesting in this respect. Clinical experiences show that surgeons could benefit from training in a 3D environment before they are exposed to patients (Ota, Loftin, Saito, Lea \& Keller, 1995). First, this is associated with better health care in terms of improvement resulting in fewer complications and shorter hospitalisation. Second, the cost of training could be reduced if it was cut

3 We will not give a detailed description of the 3D-based systems that are referred to. This is because our attention is on the collaborative knowledge construction processes and how the 3D-environement serves as a means for supporting them, and the environment's implication for how to study it. down from five to three years (Ota et al, 1995). Moreover, the standardisation of skills associated with specific procedures is considered important. Third, 3D environments provide possibilities for measuring different aspects of a procedure. This contributes to a higher level of efficiency and is as such highly content driven, but is of great importance for the quality of work. 3D environments used in surgical education have mostly been designed to train and improve procedural knowledge and skills.

In an invited review of the use of 3D environments in surgical education Qayumi \& Qayumi (1999) suggest a 'CyberPatient' as an essential part of a problem based learning curriculum. The authors argue that most 3D environments are not designed for supporting interactivity and interaction in any true sense. 3D-based computer systems developed for the purpose of supporting a doctorpatient interaction, often include elements like: taking the patient's history, physical examination of the patient, different kinds of tests, diagnosis development, treatment planning, surgery, postoperative management and follow up. This simulates the patient illness trajectory and provides rich representations of various aspects of this trajectory. As educational philosophy for designing a virtual environment, Qayumi \& Qayumi (1999) suggest a Piagetan philosophy. Within this area of use, conceptual knowledge is emphasised together with the procedural knowledge.

There are few in-depth studies that address issues connected to learning and collaboration and the outcome of these processes (McLellan 1996). One study that provides insights into these issues is the one conducted by Pilkington \& Parker-Jones (1996). The authors present a 3D-based system of which the systems design is based on several significant elements from learning theory. The medical area, which the student is exposed 
to, is the regulation of calcium of the human body. The system is based on the idea of cognitive conflict, inconsistency, and contradiction outlined from Piaget (1977). These issues are integrated with Vygotsky's (1978) concept on the zone of proximal development. In the perspective developed by Vygotsky the dialogue is one of the most important sources for learning. Articulation, self-explanation and elaboration become crucial relative to what can be learned. This combination is manifested in discourse between pairs of students, and in some of the dialogues an expert in the medical field can participate and make interventions. The objective behind the systems design was then to create an environment that mediates the student's knowledge construction beyond superficial understanding. The students found the simulation favourable (over other learning resources) because the simulation was realistic and it was thus possible to test specific hypotheses (Pilkington \& Parker-Jones, 1996). Traditional textbooks or lectures do not create possibilities of interaction with an environment nor with and expert, the way this application does. It is reasonable to argue that this application has inherent qualities, which have the potential to promote higher order processes.

The quality of the talk among the students differs between the pairs, and it is dependent upon the intervention made by the expert. When the expert made interventions the number of casual explanations and reflective turns increased. If one looks at the material as a whole, "the student-student dialogue was more likely to focus on observation, preparation and monitoring activities and less likely to focus on reasoning activities" (Pilkington \& Parker-Jones, 1996).

The results from the study by Pilkington and Parker-Jones seem reasonable both from cognitive studies in the medical domain and a more socio-cultural view of learning and cognition. Since there exist so few studies of learning processes and learning outcome from 3D environments in medicine, it is necessary to draw on the literature within medical cognition and other approaches (which have studied learning in the medical field) to enrich the interpretation of the findings presented.

Medical students do not have as well developed illness scripts as more experienced physicians (Feltovich et al, 1992), and their basic biomedical knowledge is partly encapsulated (Boshuizen et al, 1992). The term encapsulated means that the knowledge is structured in such a way that the basic biomedical knowledge is difficult to access. These difficulties could be caused by cognitive and social factors. From a socio-cultural view this finding could be interpreted as a typical way of talking among the students, that is a discourse pattern. The teacher (expert) is the person who constructs scaffolds so the dialogues can move to a more advanced level. Ludvigsen (1998) found that the teacher was the person who pointed to specific cues of vital importance when students were talking with and about patients. The teachers asked questions, which were necessary for the students to be able to construct coherence in their diagnostic activities (Gadd, 1995; Ludvigsen, 1998). The teacher also had to help the students to integrate their knowledge in relation to specific cases.

Gadd (1995) and Ludvigsen (1998) found that teachers use characterisations, reformulation, explanations and summaries to create possibilities not only for students to solve concrete problems, but also to get access to their biomedical knowledge. These aspects related to talk between students and teachers are dependent on institutional practice. The institutional practice creates constraints and affordances for the students-teacher relation. Their biomedical knowledge together with social and cultural factors define how the 
Outlines-2001-2.qxd 23-11-01 10:27 Side

OUTLINES・No. $2 \cdot 2001$

students learn to get patients' information, select information, combine information organise information in different types of documents. How physicians organise information and talk to each other could be termed as cultural scripts (Shore, 1996). Cultural scripts are part of institutional dialogues. Institutional dialogues have other features than what are found in everyday talk. Who can talk and in which order and what the participants are allowed to say follow a predefined order, which has implications for the turn taking in the situation. What is on the agenda, and which of the participants can change the agenda are also predefined (Suchman, 1987; Linell, 1990 and 1999; Ludvigsen, 1998).

To conclude the brief overview of 3D environments' potential and area of use within the field of medical education, there are two types of issues that have been focused in most designs: Technological functionality and novelty, and subject domains and associated content and pre-defined tasks. We argue that learning in 3D environments must be considered in terms of more complex approaches that view issues like subject domains, theories on learning and 3D-technologies as critical parts of interconnected activity systems. Research aimed at understanding the specific conditions of other types of learning environments (anchored in Web-based technologies) clearly shows that the students' collaborative learning processes are mediated by a set of aspects manifested in a complexity of: Theories of learning and instruction, subject domains, teachers' roles, delivery institution's educational practice and tradition, organisational and administrative arrangements, costs, and properties of technologies. (Fjuk, 1998, Fjuk \& Ludvigsen, 2001, Wasson et al., 2000). This complexity implies that it is complicated, sometimes even impossible to consider what aspects that are most critical with respect to learning and cognition. In spite of this, an awareness of the complexity in terms of possible contradictions and interdependencies is an important component in any analysis and design.

In line with this argumentation we need to create a complex understanding of how medical reasoning takes place. In several studies of clinical reasoning, social and organisational aspects are critical parts of the reasoning process (Cicourel, 1990; Ludvigsen, 1998). The knowledge developed by medical students is situated, or what Elstein (1995) terms, case-specific. The ability to implement relevant knowledge in clinical situations is not just a cognitive problem, but it is part of the institutional context where students' reasoning is part of different types of activities. In order to establish a correct diagnosis and adequate treatment, it is imperative to know when and how to apply medical knowledge.

Within such an understanding of medical activities, problem solving becomes a cognitive, social and culturally based phenomenon. This means that both the vertical and horizontal aspects of expertise become important. When focusing on the horizontal aspects of expertise teams of health workers in collaboration and communication efforts become important. These types of processes need to be analysed and understood from the view of horizontal expertise. The output from the team is their collective efforts. Vertical expertise is well studied in the area of cognitive science. The expert-novice studies show how physicians have very different knowledge structures (Schmidt, Norman and Boshuizan, 1990; Elstein, 1995). The horizontal aspects of expertise are not well studied in general, or in the field of medicine. It is possible to identify a few studies related to these questions in medicine as a field. We have already mentioned some important findings from Cicourel's $(1990 ; 1995)$ stud- 
ies. Ludvigsen (1998) made findings similar to Cicourel, both in the educational and in the work context in his study of medical students and interns. Engeström (1993; 1995) has used activity theory to analyse how physicians work in general practices. The horizontal aspects of medical expertise are shown and elaborated on, in all these studies. In Strauss, Fagerhaugh, Suczek \& Wiener (1985) studies of the social organisation of medical work show how dependent physicians are both upon each other and on other health workers.

We argue that the studies conducted by Cicourel (1990), Engeström (1993) and Ludvigsen (1998), demonstrate very clearly how complex and important the horizontal aspects of expertise are in the field of medicine. The socio-cultural view of learning and cognition represents an adequate framework for understanding this phenomenon. The students' reasoning and their actions are part of a situated practice. If we build virtual environments upon this perspective the environments become more realistic, and the knowledge the students develop becomes more valid.

To improve skills in relation to clinical situations, there is a need for tools that mediate various forms of knowledge. 3D environments could serve as tools for training in this kind of knowledge development. The students are then invited to develop mental representations, situated knowledge and the ability to participate with other health workers in collective problem-solving situations (Cicourel, 1990; Ludvigsen \& Bach-Gansmo, 1998a, 1998b).

To be able to incorporate the complexity argued in this section into analysis and designs, we need frameworks that provide insights into how humans learn, as well as what role technological artefacts and other issues occupy in the learning processes. These conceptual challenges will be the focus of the next section.

\section{Steps towards a framework for understanding and de- signing 3D environments}

$\mathrm{M}$

ost designs are based on key topics within cognitive science (e.g. memory, perceptions, reasoning skills) (Hoffman, 1998). This means that learning is considered from an information processing perspective. Winn (1997) takes another position than those placed within cognitive science. He emphasises an open constructivist approach as the premise. Concerned with premises for design and analysis, he includes both ideas from the individualistic approach and from an approach that emphasises collaboration as a central premise for learning. However, Winn (1997) does not elaborate upon central questions as units of analysis and the assumptions that are connected to the different positions he builds on.

In order to establish a new research agenda, it is necessary to move from such a focus, often represented by content-driven perspectives (in relation to a focus on mental representation and cognitive structures), to an emphasis on socio-cultural perspectives. This new research agenda can give us better accounts for the specific nature of 3D environments, and their relation to other learning technologies and the social contexts in which they are used. Such a research agenda can bring us substantial insights in what kinds of knowledge can be developed in this type of environment.

McLellan (1996) summarises other approaches which have the ambition of building frameworks for designing and understanding 3D environments. The author mentions approaches like: The ecological psychology perspective (based on J.J. Gibson's theory, where direct perception and affordances are the key terms), The computer as theatre perspective (based on Brenda Laurel's theory about drama as a metaphor for 
understanding human-computer interaction), The space maker design perspective (based on R. Walser's ideas about filmmaking, performing arts, and role-playing games), and Design theory and design metaphors as a perspective. We could add the approach influenced by storytelling, which is also part of some of the approaches mentioned. The idea behind a storytelling approach is connected to the fact that narratives are a basic element for learning and human development. The problem with these approaches is that they do not have an explicit focus on learning, cognition and collaboration. We argue that this is a fundamental condition for understanding what can be learned in 3D environments, and then judge how valuable they could be in various types of education.

\section{Theoretical foundation}

In recent years a series of alternatives to standard cognitivist approaches to learning and cognition has evolved. ${ }^{4}$ In spite of different terminologies, research traditions, and methodological preferences, the approaches share the assumption that learning has to be understood as actions and activities integrated in a complexity of social, institutional, cultural and historical practices. The unit of analysis is widened from viewing the individual as a "solo student" to including the student's practice in relation to activities in communities of practice. We will here emphasise one of these theories, which gives us a rich framework for design and empirical studies of 3D environments.

Activity theory constitutes a rich framework for studying different forms of prac-

4 These approaches are situated action (Suchman 1987), situated learning (Lave \& Wenger, 1991; Greeno, 1998), distributed cognition (Huchins 1995), cultural psychology (Cole, 1996), mediated action (Wertsch, 1991), and activity theory (Engeström, 1987; Engeström \& Miettinen, 1999). tices as developmental processes, with individual and social issues interlinked at the same time (Kuutti 1996). An important feature of activity theory is that the system is driven by a collective motive that expands beyond the level of individual intentions. Activity systems are not reducible to a sum of individual actions, they have "... cyclic rhythms and long historical half-lives" (Engeström et al, 1995). In other words, activity theory affords analyses of social phenomena on different levels; activity - at the level of social systems; action - at the level of the individual student acting intentionally; and operation - at the level of the concrete operation, procedure or behaviour. To fully understand an activity, its history and development should be taken into consideration. This expands the unit of analysis even beyond the context of one given activity system.

In an activity system there are potential contradictions or tensions between all components of the systems (Engeström, 1987). Contradictions are used to indicate 'misfit' within elements of an activity, and between different developmental phases of a single activity. Contradictions manifest themselves as problems, breakdowns, clashes, etc. within the system itself or in relation to other systems (Kuutti, 1996). The objective of Engeström's systemic model is to consider the socially based nature of human activity by including rules of communication and division of work. In agreement with Engeström's systemic model, Fjuk \& Smørdal (2000) introduce three aspects that together constitute a useful basis for understanding the nature of computer-mediated collaborative learning. The interconnected aspects are: Development of meaning and knowledge construction, exchange processes and roletaking processes. These aspects are illustrated in figure 1. The upper triangle concerns the individual student's actions directed to- 
wards knowledge construction and thought, - mediated by a constellation of artefacts that are situated within the 3D environment. The model shows that a student is not isolated but is a part of a 3D-generated learning community, represented by the aspects of exchange and role-taking processes. The exchange processes thus concern the student's actions directed towards the shared learning community, - mediated by the embedded rules of that community (laws, traditions, physical distances, etc.). The role-taking processes concern computer-mediation of actions directed towards the shared community's division of tasks and responsibility.
An individual's actions will then be affected by three major factors: the artefacts used, the 3D environment she belongs to and its explicitly or implicitly expressed rules, and the division of work within that community of students. These factors interact in the creation of the social practice, and contradictions within the system influence the whole collaborative situation. When the unit of analysis expands to the interaction between different activity systems, the complexity that we are dealing with increases. Figure 1 illustrates these issues, focused through virtual 3D learning environments.

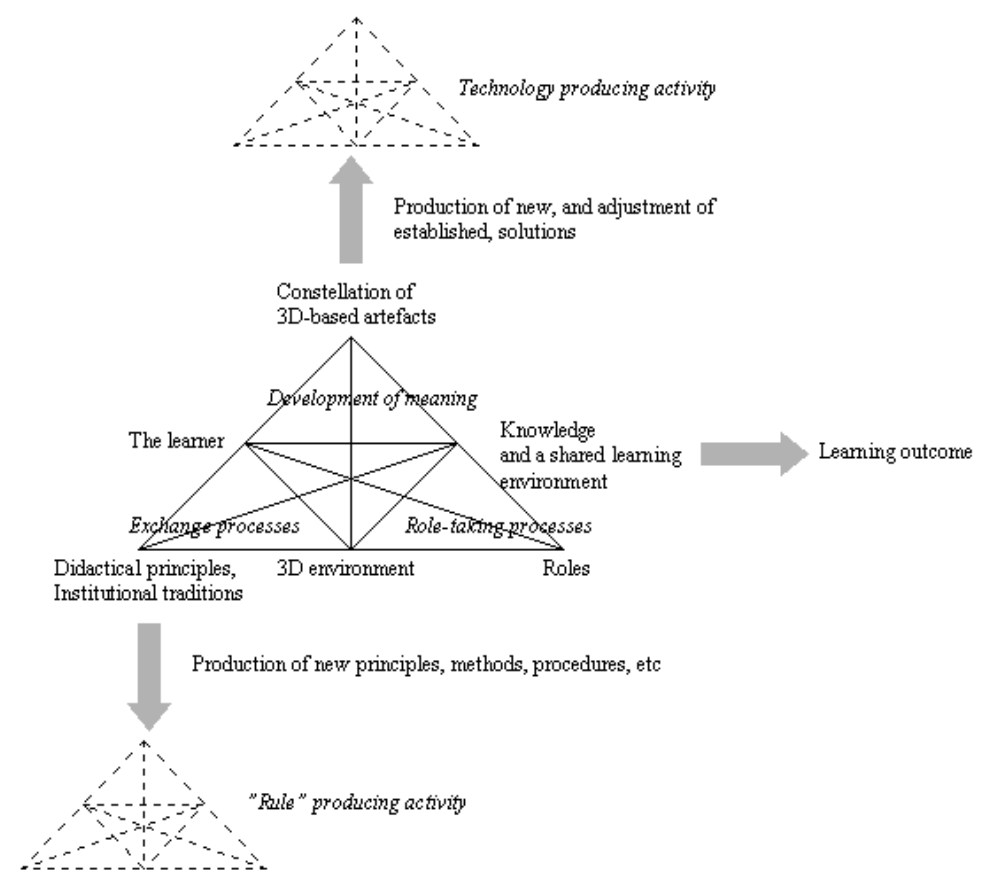

Figure 1: Activity analysis of 3D environments (Inspired by Engeström (1987))

By using activity analysis on 3D environments, it would include all use activities, tool producing activities, all teaching and knowledge construction activities, as well as changes and contradictions in the use activi- ties. This complexity makes it difficult to identify and delimit the activity systems that are of interest for the analysis (Bødker, 1996). As such, we do not need to analyse all the systems, but to be aware of contradictions 
between the activities a student is influenced by in her development of meaning and knowledge construction. Figure 1 illustrates how certain didactical principles, institutional traditions as well as the community's collection of artefacts mediate a student's relationship with the 3D environment. Furthermore, the community's commitment to the development of a shared learning environment and individual knowledge is mediated by the roles embedded in the collaboration (e.g. the power each wields, tasks each is responsible for, etc.).

The figure also illustrates how contradictions associated with didactical principles and the 3D environment lead to production of new didactical principles and technological solutions, respectively. In analysis, and in designs also, this complexity can be operationalised in terms of questions like: How do the constellation of artefacts serve as mediators for the student's actions directed towards development of meaning, as well as towards the development of a shared learning community? How do the didactical principles mediate the student's action in the 3D community? How do established institutional traditions mediate the community's distributed work and progress? In what follows, design principles from these key issues of socio-cultural theories in general and activity theory in particular are outlined. The usefulness of the principles are shown through an example, the 3D environment labelled Matador.

\section{Design principles for 3D-} mediated learning environments. Matador: An example

$\mathrm{T}$ his section provides design principles that are operationalised from sociocultural perspectives where learning is considered to be the student's "ability to use a particular set of tools in productive ways and for particular purposes" (Säljö, 1999, pp. 147). In agreement with this basic issue, new designs of 3D environments must carefully consider what role 3D-based mechanisms should entail in social interaction and in reflection. The section includes ideas of how the key principles should be applied in new designs associated with the environment developed in the MATADOR project.

\section{Matador}

The project MATADOR (Medical Advanced Training in an Artificial Distributed Environment) is aimed at developing a simulation environment for training in emergency medicine. The environment enables a group of students to communicate and collaborate in a networked and 3D-generated collaborative environment ${ }^{5}$. Figure 2 shows one part of the 3D environment. The students are aimed at being distributed in different geographical locations $^{6}$. In the 3D environment, the students are represented by avatars, which are human like 3D figures. The avatars are the eyes and the hands of the students. Both a mouse and a haptic device will be used.

\footnotetext{
5 The technological platform for the development of Matador is DOVRE API (Hagen, 1999). DOVRE API provides possibilities for integrating multimedia technologies such as sound, video, speech, and tactile feedback.

6 In what follows we use Matador to term the 3D environment.
} 


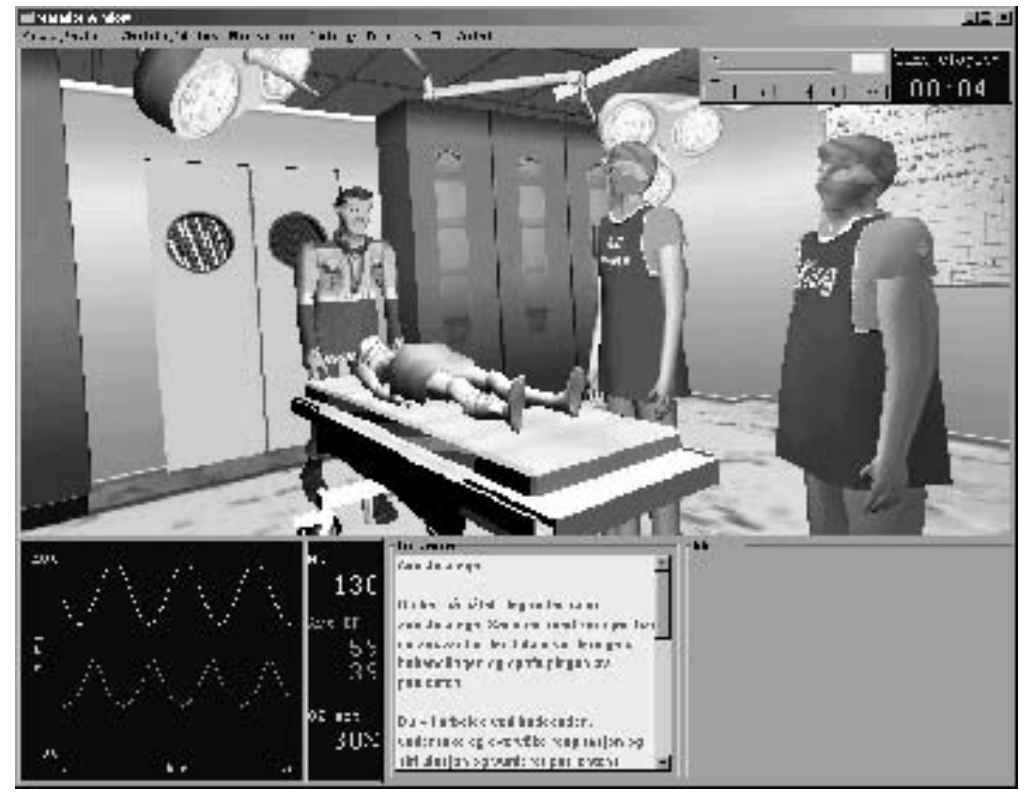

Figure 2: A patient arrives at the operating theatre. The doctors, the patient and the ambulance driver are all avatars, but the student's actions are represented by the doctor-avatars.

The Matador environment will be developed with a particular focus on communication, collaboration and leadership in teams among health professionals. In the teams there will be physicians and other health workers, which means that the social complexity of health work is built into the application. The horizontal dimensions of expertise are significant for the problem solving process. The 3D environment will enable concurrent tutoring, feedback, and evaluation of all the participants. $^{7}$ The haptic device gives the

7 The content associated with the application is inspired by a Norwegian course in trauma medicine. The group behind this course has worked with a concept 'Improved quality and systematic trauma treatment'. The course is grounded upon recommendations from the ATLS (Advanced Trauma Life Support) (Bratteb $\varnothing$ et al., 1998/99). This concept is developed by the American College of Surgeons, and is considered a standard in emergency medicine (Bell et al., 1999). students possibility to get in 'touch' with the 'patient'. The team exposed to the 3D environment will perform different cases. In these cases the life-threatening conditions are built in and can be activated dependent on the students' actions. The team have to talk, act and create specific activities and revise their action and activities in a collaborative effort to solve the problem inherent in the cases. One example of this is when the blood pressure falls and there is an increase in the heart rate. This must be detected and the team has to communicate about this and find solutions to the problem. The history of the patient is part of the cases, but the context for the team is in an emergency room in a hospital. After a team has performed the cases, there will be debriefing sessions with an experienced supervisor. 
Operationalising the theory for design In-depth studies of Web-based environments (Fjuk, 1998; Smørdal, 1999) show that an individual actor's computer applications hampered the actions directed towards the exchanging- and role-taking processes (cf. figure 1). A simple example is: A painting program is a potential tool for linking thought and articulation of it into drawings. Using the program is quickly routinised, but because of software incompatibility between the collaborative actors' programs, the thoughts manifested into drawings did not appear as appropriate means for collectively articulating the actors' argumentation and negotiations of meaning. The constellation of computer-based artefact (in use) hampered the mutual relationship between individually and collectively oriented actions. The operation of the action was not conducted automatically, - thoughts are directed towards the artefact itself. Due to internalisation of the properties and behaviour of the computer-based artefacts, the artefacts did not become integrated parts of the actor's actions. Rather, the use of networked computers involved thought that stemmed from problems of using them due to breakdowns or due to unfamiliarity with them.

These observations clearly indicate the challenge of designing virtual learning environments in which various computer-based artefacts have an essential role in learning and social interaction. Seen from a computer systems designer's standpoint, the relation between individually and collaboratively oriented interactions often conflict, forcing designers to make computer-based mechanisms for one at the expense of the other (Gutwin \& Greenberg, 1998). Design that supports individual actions often hinders collaboration, and vice versa. For example, this trade-off becomes apparent when trying to support both the individual's needs of integrated and transparent tools and control over the artefacts, and the collaborative community's needs regarding information sharing, division of work, creation of joint understanding, etc. Based on these observations and studies, Fjuk \& Smørdal (2001) have developed a framework that is aimed at guiding systems designers in their process of structuring the analysis concerning the role of computer-based artefacts in collaborative learning. The authors argue that systems design has to be aimed at understanding the communicative aspect of action in order to offer good solutions for the operational aspect. To support the mutual interplay between individual and collective processes of the learning activity, the challenge is found in the duality and interplay between the aspects presented in figure 1 .

Although many artefacts have a double position of mediating both the communicative aspect of an action and the operational aspect of the same action, this is an essential property of computer applications in general (Fjuk \& Smørdal, 2000) and of 3D environments in particular. For example, group decisions and common plans (manifested in e.g. activity responsible charts) and joint productions (manifested in e.g. project report) are potential signs (i.e. the communicative aspect) for the exchange- and role-taking processes. Technology such as groupware systems, co-authoring software, project management software, etc. are potential tools for operationalising the actions directed towards these signs and for making changes upon them. The interplay between the individualistic and collective aspects (in figure 1) exhibits very differently in $3 \mathrm{D}$ environments than in e.g. Web-based environments. 3D environments offer richer opportunities of feeling the presence, sharing time and space, observing the actions of others, etc. These typical features of 3D environments imply that the operation of individual actions becomes explicit and visual in the shared 
3D-based learning environment. This means that the mutual relationship between actions directed towards development of meaning and collective processes, becomes more transparent than in other virtual environments (Krange et al., 2000). Thus, the interplay between the three aspects, and embedded actions, becomes even more interwoven and blurred than in e.g. text-based and asyn- chronous environments (as in most Webbased environments).

Table 1 illustrates the three aspects in terms of various awareness issues. The communicative part of an action is focused, since the operationalised part is more or less associated with a concrete 3D-technology and environment.

\section{Aspects The role of signs and tools in collaborative learning}

Development of meaning Various 3D mechanisms (such as objects, avatars and oral speech) are targeted toward the aim of human activity. Some are means for changes upon the aim of human activity, while others are aiding thought and reflection upon the aim. Concept awareness is a means towards this aspect.

Exchange processes Some 3D mechanisms and human actions mediate thought, knowledge and perspectives among students participating in the 3D environment. Other 3D mechanisms are means for changes upon objects. Task awareness is a means towards producing a common task.

Role-taking processes

Some 3D mechanisms mediate the division of tasks and responsibility, like common decisions, commitments, and work arrangements. Various types of shared mechanisms are means for a community to collectively make changes upon an object and to be aware of the patterns of action in the 3D environment. Social- and workspace awareness are means in this context.

Table 1: The role 3D mechanism (like e.g. objects, avatars and oral speech) in 3D environments.

As indicated in table 1, awareness information is a notion that is particularly interesting in this context, and that has been focused in computer systems designs to reduce the meta-communicative efforts needed to collaborate across physical distances and in computer-mediated environments (e.g. Gaver, 1991; Dourish \& Bellotti, 1992; Palfreyman
\& Rodden, 1996; Gutwin et al., 1995; Gutwin et al., 1996). Dourish \& Bellotti (1992) introduced the concept of awareness, connected it to shared workspaces and defined it as "an understanding of the activities of others, which provides a context for own activity" (ibid. p. 107). Moreover, Gutwin et al. (1995) understand workspace awareness 
as "the up-to-the-minute knowledge about other students' interactions" and proclaim that such information plays an "integral part in how well an environment creates opportunities for collaborative learning" (ibid. p. 147). Gutwin et al. (1995) suggest three additional categories of awareness information that should be considered with respect to collaborative learning. Social awareness concerns social aspects of how to participate in a group or community. The students must make decisions about what role they must have in a particular community, what they should expect of the other actors and how they want to interact with people in the community, etc. Moreover, a collaborative environment is made up of many tasks carried out over time, and divided according to various situated criteria amongst the students. This particular feature of collaboration concerns issues that Gutwin et al. (1995) call task awareness. Task awareness is concerned with how to complete the common task (e.g. What do we know about the task, how much time do we have, what steps must we take to complete the task, etc.). Gutwin et al.'s categories of social awareness and task awareness correspond with what Fjuk \& Smørdal (2001) term role-taking processes. A third category of awareness suggested by Gutwin et al. (1995), concept awareness, is more directly related to the knowledge construction process. The student must activate what they already know about the problem at hand and need to find ways of how to achieve new knowledge so as to fulfil the task.

Outlined from socio-cultural principles in general and the framework in table 1 in particular, Fjuk \& Krange (1999) and Krange et al. (2000) suggest three relationships that particularly characterise 3D environments. These are actor-object ${ }^{8}$, object-object and,

8 It is important to note that the term "object" is here understood as a $3 D$-generated object, and does not necessarily refer to an object in an activity theoretical perspective. actor-actor. In line with the theoretical heritage, and in agreement with the framework developed by Fjuk \& Smørdal (2001), the relationships cannot be considered separately but mutually. Concerning the first, the actorobject relationship, it represents first and foremost a student's actions mediated by an object embedded in the 3D-environment. This operationalisation is conducted by manipulating the object directly by clicking, lifting, moving, etc. The actor-object relationship clearly supports awareness information of how a task is completed. This is because the students internalise the same images and this ability reduces the need to meta-communicate all interactions. As such, the result of the operation functions as a visible sign for the co-students, guiding them to individual reflection and further action. Fjuk \& Krange (1999), however, discuss whether it is necessary to achieve knowledge regarding who is doing what, how, where and when in all parts of the collaboration. As suggested, the designs' ideals thus become to create opportunities for the student to move between closeness to co-students through some extent of workspace awareness, and a distance to peers in order to articulate thoughts through reflection.

The second relationship, the object-object relationship concerns how manipulation on one object influences the situated conditions of another object. This object-object relationship has a twofold effect on collaborative learning and awareness information. On the one hand, it explicitly visualises the consequences of the individual's actions on an object and constitutes an essential sign for further actions related to divisions of tasks and discussions about the tasks. On the other hand, it mediates the student's information awareness on how their action constitutes a part of a greater wholeness. This is an essential factor in how well an environment creates opportunities for collaborative learning, 
rather than workspace awareness and task performance per se (ibid.).

The last relationship, actor-actor relationship, concerns the social interactions and to some extent what Gutwin et al. (1995) term social awareness. Fjuk \& Krange (1999) argue that efficient task performance is not sufficient for providing learning effects of 3D environments. Rather, the learning effects of collaboration become optimal when the virtual environment creates opportunities for discussions and argumentation about the tasks (cf. Dillenbourg, 1996). Oral dialogues between the actors may mediate this interaction, but also by the two other relationships (actor-object, object-object). This argument particularly supports a need for explicitly considering the situated effects of awareness information, and thus in terms of the dynamic interplay which the framework of table 1 underlines. One way to provide learning effects of this situatedness is to organise for good interactional conditions so that they stimulate the student's mindful engagement, personal responsibility and discussions (Fjuk \& Krange, 1999). Although design of 3D environments is explicitly related to the subject domains, the specific problem area and its contents (more than e.g. Web-environments), this is first and foremost connected to the $e x$ ternal goal of the learning activity, and not necessarily to the $3 \mathrm{D}$ environment in itself. In line with this argument, Storås (2000) emphasises that design of $3 \mathrm{D}$ environments must strive to define a rather complex object of the learning activity, so as to force social interactions and reflection. In spite of their similarities to physical and co-located learning environments, 3D environments do not, in their own right, stimulate social interactions and reflection.

The discussed design principles give some directions for new designs associated with the Matador-environment and medical education: First, the goal of the learning ac- tivity must be complex in the sense that it stimulates to reflections and collective processes. In the Matador case, this issue is closely related to practical examples and various simulations of practice. These examples and simulations must be designed so as to challenge current knowledge and meaning, and furthermore stimulate to discussions and sharing of reflections amongst the students. An example of this issue is when the students, through their communication in the shared 3D environment, have access to a variety of medical information as test results, information from instruments about the heart condition, blood pressure, X-rays etc, and they have to reach a common understanding and act collectively based on their understanding of the actual and evolving situation. Figure 3 illustrates such a situation.

This process could be related to both further diagnostic activity and treatment of the patient.

This leads us to the second issue, that is, the necessary relationship between individual and collective processes. The social interactions (e.g. operationalised in terms of the actor-actor relationship) must not necessarily take place within the virtual environment. Rather, they can take place outside it, - in a traditional physical situation or in other types of virtual environments. The 3D-generated artefacts may, together with other types of artefacts, serve as tools for mediating the mutual interplay between individual and collective processes. The situated effects of various awareness issues must be consciously considered in this respect. To consider 3D environments as closed systems could be misleading when trying to understand their impact on learning processes. The learners will use knowledge from previous experiences in the same types of situations. The activities in the $3 \mathrm{D}$ environment are part 


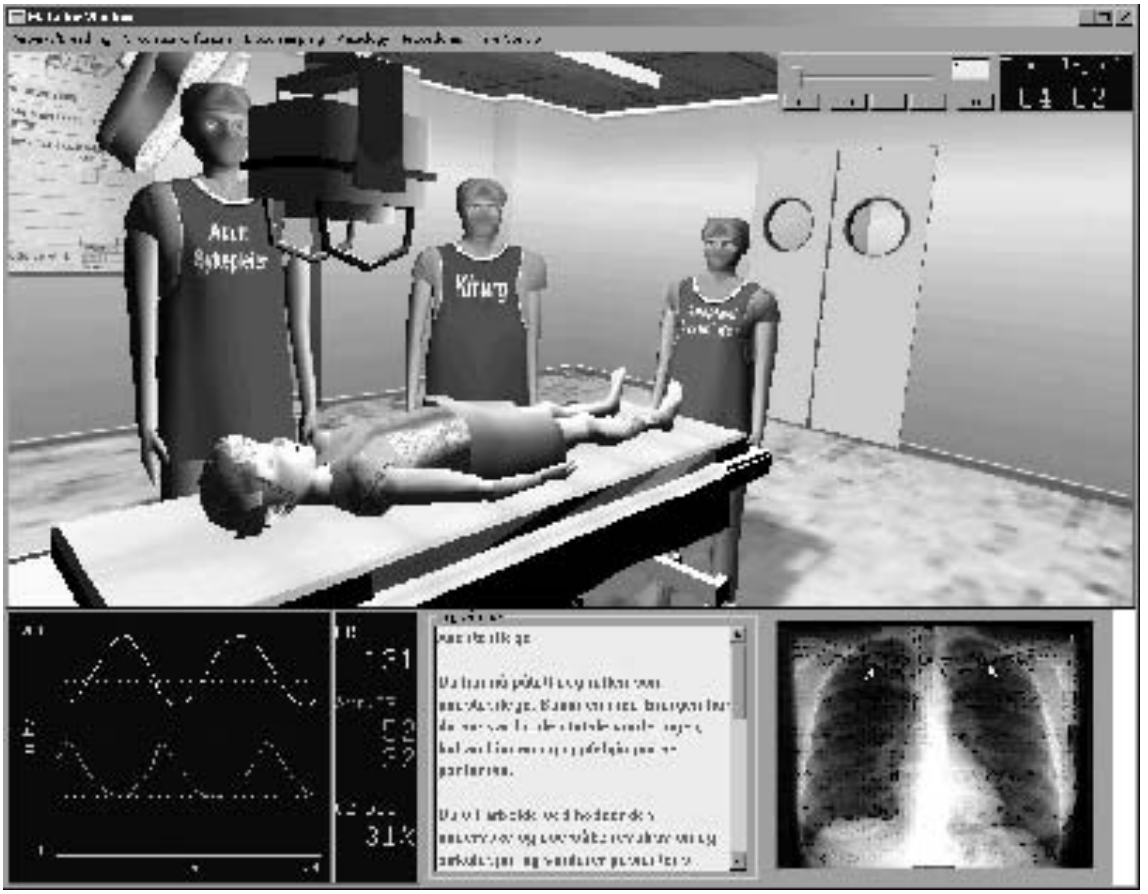

Figure 3: The students collaborate in the shared 3D environment and have access to medical information like $X$-rays

of their learning trajectory, which is stretched out over activities in different settings.

When it comes to the actor-object and object-object relationships, they must be consciously considered with respect to the goal of the learning activity. For example, the actor-object relationship should be designed so as to provide feedback related to how different diagnostic activities are connected. When a student investigates the abdomen, the 3D environment can give feedback about what type of pain and the location of pain. The students' interpretation of this finding gives direction for how to proceed. This can be approached by various operations on the patient. The object-object relationship can be used to simulate what happens with the patient when the blood pressure decreases and how this and other biological processes in different organs are affected (or not affected) by each other. This will create situations where the systemic nature of the human body becomes more transparent. The action performed by the students influences on other processes than the interventions are directed towards. A set of unpredictable events will create the environment, which actually shows the situated nature of problem solving in a dynamic environment. The learning environment becomes realistic, because the problem solving process is dependent on how the students are able to create a collective effort. Without this collective effort the degree of distributed expertise for solving the problem will not be reached. 
20

\section{Conclusion}

$\mathrm{W}$ have argued that the socio-cultural perspectives (with activity theory as the major example) provide us with a more adequate understanding of learning processes in 3D environments, than approaches based on information processing perspectives on human learning. These perspectives give us important directions for the design of 3D environments where students use various types of resources, including artefacts and the knowledge owned by co-students. The theoretical framework also affords the opportunity for understanding the learning processes, which take place in the 3D environment in relation to the other activity systems of which the student is a part. The latter argument is of particular theoretical and methodological importance, since this is not the case in most CSCL research nor in the field of using 3D environments in medicine. If we expand the unit of analysis and analyse learning processes as part of activities on different levels, we will be able to develop a better understanding of learning in technology rich environments and how these learning processes are related to other activity systems. These types of analyses will be useful for several purposes. First, they contribute to an understanding of the learning processes taking place in 3D environments, other clinical situations and their relation. Second, they provide guidelines for designing courses and larger units in professional education. And last, they provide us with ideas for clarifying the educational benefit of using 3D environments as tools for learning in relation to learning in other forms of tools and representational media.

In the 3D environment described - Matador - it is possible to study collaboration, communication and how cognition is distributed, in detail. This can give us new insights into the efficiency of 3D environments associated with problem solving situations and how different types of expertise relate to each other. Studies of vertical and horizontal aspects of expertise will give us possibilities to discuss how these types of expertise could be understood when they are parts of collaborative efforts.

\section{Acknowledgement}

We want to thank Telenor R\&D, Nordunet 2, and the University of Oslo for financial support to this research. We also want to thank project leader Ragnhild Halvorsrud and the members of the team involved in the development of Matador for discussions which have helped frame the argumentation in this article. Ivar Kjellmo has developed the graphical design for the environment.

\section{Literature}

Bell R.M., Krantz B.E., Weigelt J.A. (1999): ATLS: a foundation for trauma training. Ann. Emerg. Med. 34: 233-7

Berge, O. (1997): Making Distance Education Collaborative through Internet. Transcending the Traditions of Distance Education and Collaborative Learning. Cand. Scient. thesis, Department of Informatics, University of Oslo, Norway.

Boshuizen, H.P.A., Hobus, P.P.M., Custers, E.J.F.M, \& Schimdt, H.G (1992): Cognitive Effects of Practical Experience. In Evans, D.A. and Patel, V.L. (Eds.) Advanced Models of Cognition for Medical Training and Practice (337-348). NATO ASI series Vol.97.

Bratteb $\varnothing$ G., Wisborg T., Bratteb $\varnothing$ J., Kvitting P., Aksnes A., \& Brinchmann-Hansen, Å. (1998/ 99) Kvalitetssikring av traumebehandling i sykehus. Internal note, the Norwegian Medical Association.

Brown, A. (1992): Design Experiments: Theoretical and Methodological Challenges in Creating Complex Interventions in Classroom Settings. The Journal of the Learning Sciences, Vol. 2, 2, 141-178. 
Brown, A.L., Ellery, S. og Campione, J.C. (1998): Creating Zones of Proximal Development Electronically. In Greeno, J.B. \& Goldman, S.V. (Eds). Thinking Practices in Mathematics and Science Learning (341368). New Jersey. Lawrence Erlbaum Ass.

Cole, M. (1990): Cultural psychology: A once and future discipline? In Berman, J.J. (Eds.) Cross-cultural Perspectives. Nebraska symposium on motivation. Lincoln: University of Nebraska Press.

Cole, M. (1996): Cultural Psychology. A once and future discipline. Cambridge Mass.: Harvard University Press.

Clancy, W.C.(1997): Situated Cognition. On Human Knowledge and Computer Representation. Cambridge; Cambridge University Press.

Cicourel, A.V. (1990): The Integration of Distributed Knowledge in Collaborative Medical Diagnosis. In Galegher, J., Kraut, R.E., \& Egido, C. (Eds.) Intellectual Teamwork. Social and Technological Foundations of Cooperative Work (pp. 221-242). Hillsdale, New Jersey: Lawrence Erlbaum Ass.

Cicourel, A.V. (1995): The Interaction of Cognitive and Cultural Models in Health Care Delivery. Presented at the 9th conference of European Health Psychology Society. Bergen, Norway.

CTGV (1997): The Jasper Project. Lessons in Curriculum, Instruction, Assessment, and Professional Development. New Jersey: Lawrence Erlbaum Associates Inc.

Dourish, P. \& Bellotti, V. (1992): Awareness and Coordination in Shared Workspaces. Turner, J.; Kraut, R. (Eds.): CSCW-92. Sharing perspectives. Proceedings of the Conference on Computer-Supported Cooperative Work, pp. 107-114. ACM Press.

Dillenbourg, P. (1996) Some technical implications of distributed cognition on the design of interactive learning environments. Journal of Artificial Intelligence in Education, 7 (2), 161-179.

Elstein, A.S. (1995): Clinical Reasoning in Medicine. I Higgs, J. \& Jones, M. (Eds.). Clinical Reasoning in the Health Professions (pp. 49-59). Oxford: Butterworth-Heineman.
Engeström, Y. (1987): Learning by expanding: An activity-theoretical approach to developmental research. Helsinki: Orienta-Konsultit.

Engeström, Y. (1993): Developmental studies of work as a testbench of activity theory: The case of primary care medical practice. In Chaiklin, S \& Lave, J.(Eds.) Understanding practice, Perspectives on activity and context (s. 3-34) N.Y.: Cambridge University Press.

Engeström, Y. (1995): Objects, contradictions and collaboration in medical cognition: an activity-theoretical perspective. Artificial Intelligence in Medicine, 7, 395-412.

Engeström, Y. \& Miettinen, R. (1999): Introduction. In Perspectives on Activity Theory (Eds.) Engeström, Y., Miettinen, R., Punamäki, R.L. Cambridge. Cambridge University Press.

Feltovich, P.J., Coulsen, R.L., Spiro, R.J., \& Dawson-Saunders, B.K. (1992): Knowledge Application and Transfer for Complex Tasks in Ill-structured Domains: Implications for Instruction and Testing in Biomedicine. In Evans, D.A. og Patel, V.L. (Eds.) Advanced Models of Cognition for Medical Training and Practice (213-244). NATO ASI series Vol. 97.

Fjuk, A. (1998): Computer Support for Distributed Collaborative Learning. Exploring a Complex Problem Area, Dr. Scient Thesis, Department of Informatics, University of Oslo.

Fjuk, A.\& Dirckinck-Holmfeld, L. (1997): Articulation of Actions in Distributed Collaborative Learning. In Scandinavian Journal of Information Systems, Vol. 9, No. 2, 3-24.

Fjuk, A. \& Krange, I. (1999): The situated effects of awareness in distributed collaborative learning: Interactive $3 \mathrm{D}$ an example. In Hoadley, C. \& Roschelle, J. (Eds.) Proceedings for: Computer Support for Collaborative Learning. Designing New Media for a New Millenium: Collaborative technology for learning, Education and Training. Stanford University.

Fjuk, A.\& Ludvigsen, S. (2001): The Complexity of Distributed Collaborative Learning: Unit of Analysis. In Dillenbourg, P., Eurelings, A. \& Hakkarainen, K. (Eds.) EC$S C L$ - European Perspectives on Computer- 
Supported Collaborative Learning. Proceedings of E-CSCL: University Maastricht.

Fjuk, A. \& Smørdal, O. (2001): Incorporating networked computers in collaborative learning. In Dillenbourg, P., Eurelings, A. \& Hakkarainen, K. (Eds.) ECSCL - European Perspectives on Computer-Supported Collaborative Learning. Proceedings of E-CSCL: University Maastricht.

Gadd, C.S. (1995a): Ruminate: A model of the multiple roles of diagnosis in the communication and evaluation of expertise. $\mathrm{PhD}$, University of Pittsburgh.

Gaver, W. (1991): Sound Support for Collaboration. Proceedings ESCW'91, 293-308.

Gorman, Meier, \& Krummel, (1999): Simulation and Virtual Reality in Surgical Education. Archives of Surgery, Vol 134, No. 11 (http://archsurg.ama-assn.org/issues/ v134n11/full/ssa9016.html).

Grenno, J.G. \& Moore J.L. (1993): Situativity and Symbols: Response to Vera and Simon. Cognitive Science. Vol. 17, No 1, 49-61.

Greeno, J. (1998): The Situativity of Knowing, Learning, and Research. American Psychologist, January, Vol. 53, No.1, 5-26.

Gutwin, C., Stark, G. \& Greeberg, S. (1995): Support for Workspace Awareness in Educational Groupware.

Schnase, J. L. \& Cunnius, E. L. (Eds.): Computer Support for Collaborative Learning. Proceedings of CSCL'95. The First International Conference on Computer Support for Collaborative Learning (147-156). New York: Lawrence Erlbaum Associates.

Gutwin, C. \& Greenberg, S. (1998) Design for Individuals, Design for Groups: Tradeoffs between power and workspace awareness. In Proceedings of the ACM Conference on Computer Supported Cooperative Work. ACM Press, 207-216.

Gutwin, C., Roseman, M. \& Greenberg, S. (1996): A Usability Study of Awareness Widgets in a Shared Workspace Groupware System. In Proceedings of ACM CSCW'96. Conference on Supported Cooperative Work. Boston, Mass, ACM Press.

Hadzimahmutovic, Z., Healy, D., Tsaltas, J., Lawerence, A.S., Brown, T. \& Flanagen, B. (1999): Gynaecological endoscopy training simulators, Gynaecological endoscopy 8, 129-135.

Hagen, S. (1999): DOVRE white paper. Internal report, Telenor $R \& D$.

Hoffman, H. \& Vu, D. (1997): Virtual Reality: Teaching Tool of the Twenty-first Century?. Academic Medicine, Vol. 72, No 12/ December, 1076-1081.

Hoffman, H.G. (1998): Virtual Reality: A New tool for interdisciplinary psychology research. CyberPsychology \& Behavior: The impact of the Internet, Multimedia and Virtual reality on Behavior and Society, 1, 195-200.

Hutchins, E. (1995): Cognition in the Wild. Cambridge, Ma.: The MIT Press.

Johnson, W. L., Rickel, J. W. \& Lester, J. C. (2000): Animated Pedagogical Agents: Faceto-Face Interaction in Interactive Learning Environments. International Journal of Artificial Intelligence in Education, 11, 2000.

Krange, I. et al (2000): Collaborative learning in schools by distributed use of interactive 3D technology. FoU report 18/2000.

Krapichler, C., Haubner, M., Engelbrecht, R. \& Englmeier, K.H. (1998): VR interaction techiques for medical imaging application. Computer Methods and Programs in Biomedicine, 56, 65-74.

Kutti, K. (1996): Activity Theory as Potential Framework for Human Computer Interaction Research: In Nardi, B. (ed.) Context and Consciousness. Activity and Human-computer interaction. London: The MIT Press.

Jonassen, D.H. \& Land, S.M. (2000): Theoretical Foundations of Learning Environments. New Jersey: Lawrence Erlabaum Ass.

Larsen, A. \& Krange, I. (2000): Analysing learning and collaboration in distributed 3D learning environments. Working paper, Telenor $\mathrm{R} \& \mathrm{D}$.

Lave, J. \& Wenger, E.(1991): Situated Learning: Legitimate Peripheral Participation. New Jersey: Cambridge University Press.

Lehtinen, E., Hakkarinen, K., Lipponen, L., Rahikainen, M. \& Muukkonen, H. (1999): Computer supported collaborative learning: A review of research and development. In J.H.G.I Giebers Reports on Education, 10. Department of Educational Science. University of Mijmegen, The Netherlands. 
Linell, P. (1990): De institutionaliserade samtalens elementäre former: om möten mellan professionella och lekmän. Forskning om utbildning, Vol. 4, 18-35.

Linell, P. (1998): Approaching Dialogue. Talk, interaction and contexts in dialogical perspectives. Impact: Studies in Language and Society. Amsterdam: John Beenjamins Pub. Company.

Ludvigsen, S.R. (1998): Laring i medisinsk utdannings- og arbeidskontekst. Avhandling for dr.polit graden. Pedagogisk forskningsinstitutt. Universitetet i Oslo. (Learning medicine in an educational and a work context.)

Ludvigsen, S.R. \& Bach-Gansmo, E. (1998a): Report from the project: Effects of multimedia applications in medical education related to practical procedures. Working paper (In Norwegian).

Ludvigsen, S. R., \& Bach-Gansmo, E. (1998b): Learning medical procedures. Analyzing medical multimedia applications. Working paper (In Norwegian).

Mantovani, G. (1996): New Communications Environments. From Everyday to virtual. London: Taylor \& Francis.

McLellan, H. (1996): Virtual Realities. In Jonassen, D.J. (Ed.) Handbook of Research for Educational Communications and Technology. New York: Macmillian.

Nielsen, K. \& Kvale, S. (1997): Current issues of apprenticeship. Nordisk Pedagogik (Special Issue: Apprenticeship-Learning as Social Practice) Vol. 17, No. 3, 130-139.

Ota, D., Loftin, B., Saito, T., Lea, R. \& Keller, J. (1995): Virtual Reality in Surgical Education. Comp. Biol. Med. Vol. 25, No. 2, 127-137.

Palfreyman, K., Rodden, T. (1996): A Protocol for User Awareness on The World Wide Web. In Ackerman, M. S. (ed.) ACM 1996 Conference on Computer Supported Co-operative Work. Cooperating Communities. Proceedings, ACM Press, 130-139.

Piaget, J. (1977): The development of thought: equilibration of cognitive structures. New York. Viking.

Pilkington, R. \& Parker-Jones, C. (1996): Interacting with Computer-Based Simulation: The role of Dialogue. Computers Educ. Vol. 27, No. 1, 1-14.
Qayumi, A.K. \& Qayumi, T. (1999): ComputerAssisted Learning: cyberPatient - A Step in the Future of surgical education, Journal of investigative Surgery, 12, 307-317.

Salomon, G (1992): What Does the Design of Effective CSCL Require and How Do We Study Its Effects? Sigcue Outlook, 21(3), Spring 1992, ACM, 62-68 (http://wwwcsc195.indiana.edu/csc195/outlook/62_Salomon.html).

Shore, B. (1996): Culture in Mind - Cognition, Culture, and the Problem of Meaning. New York: Oxford University Press.

Strauss, A., Fagerhaugh, S., Suczek, B. \& Wiener, C. (1985): The social organization of medical work. The University of Chicago Press: Chicago.

Suchman, L. (1987): Plans and Situated Actions. The problems of human-machine interaction. Cambridge: Cambridge University Press.

Sundar T. (1999) Simulering - øvelse som gjør mester. Tidsskr. Nor. Lageforen. 119:2700-01

Säljö, R. (1999): Learning as the use of tools: a sociocultural perspective on the human-technology link. In Littleton, K. \& Light, P. (Eds) Learning with Computers. Analysing productive interaction (44-161). London. Routledge.

Vygotsky, L.S. (1978): Mind in Society. Cambridge: Harvard University Press.

Wasson, B., Gurbye, F. \& Mørch, A. (2000): Projects DoCTA: Design and use of Collaborative Telelearning Artefacts. Reports from ITU, University of Oslo: UniPub.

Wenger, E. (1998): Communities of Practice. Learning, Meaning, and Identity. Cambridge. Cambridge University Press.

Wertsch, J. V. (1991): Voices of the Mind. A Sociocultural Approach to Mediated Action. Cambridge MA.: Harvard University Press.

Wertsch, J.V. (1998): Mind as Action. New York: Oxford University Press.

Winn, W. (1997): The Impact of ThreeDimensional Immersive Virtual Environments on Modern Pedagogy. HITL Technical Report R-97-15. Paper for NSF Workshop.

Youngblot, C. (1998): Educational use of virtual reality. Alexandria: Institute for Defense Analyses. 